\title{
FUNGSI DAN PELESTARIAN ALAT MUSIK SUNAI DI KABUPATEN MUKOMUKO PROPINSI BENGKULU
}

\section{FUNCTION AND PRESERVATION OF SUNAI MUSICAL INSTRUMENTS IN MUKOMUKO DISTRICT, BENGKULU PROVINCE}

\author{
Rois Leonard Arios \\ Balai Pelestarian Nilai Budaya Sumatera Barat \\ Jl. Raya Belimbing No. 16 A. Kuranji Kota Padang \\ E-mail: rolear72@yahoo.co.id \\ DOI: $10.36424 / j p s b . v 5 i 1.40$ \\ Naskah Diterima:22 Mei 2019 Naskah Direvisi:26 Mei 2019 Naskah Disetujui: 01 Juni 2019
}

\begin{abstract}
Abstrak
Sunai adalah alat musik utama pengiring tari gandai. Dalam mitologi suku bangsa Pekal, mereka mengenal tokoh Malin Deman yang menciptakan sunai untuk mengiringi tari gandai yang ditarikan oleh dayang-dayang. Walaupun berasal dari suku bangsa Pekal, masyarakat Kabupaten Mukomuko yang multi etnis menjadikan alat musik sunai sebagai bagian dari kesenian mereka. Pertanyaannya adalah bagaimana fungsi sunai bagi masyarakat dan upaya pelestariannya sehingga tetap eksis. Penelitian dilakukan dengan pendekatan kualitatif dengan wawancara, pengamatan, dan studi pustaka sebagai alat pengumpul data. Hasil penelitian menggambarkan bahwa sunai menjadi pemersatu masyarakat yang beraneka ragam budaya dan menjadi milik bersama masyarakat Kabupaten Mukomuko. Hal ini terlihat dari semakin banyaknya pemain sunai dan tampil mengiringi tari gandai. Pemerintah Kabupaten Mukomuko juga melakukan berbagai kegiatan agar sunai semakin dikenal oleh masyarakat.

Kata kunci: sunai, fungsi musik, pelesatrian, multietnis
\end{abstract}

\begin{abstract}
Sunai is the main musical instrument accompanying the gandai dance. In the mythology of the Pekal tribe, they know the character Malin Deman who created the sunai to accompany the gandai dance danced by ladies in waiting (dayang-dayang). Despite being from the Pekal ethnic group, the multi-ethnic Mukomuko Regency community made sunai musical instruments as part of their arts. The question is how the function of sunai for the community and its preservation efforts to maintain sunai. The study was conducted using qualitative approach with interviews, observations, and literature as a data collection tool. The results of the study illustrate that sunai is a unifying community of diverse cultures and belongs to the community of Mukomuko Regency. This can be seen from the increasing number of sunai players appearing to accompany the gandai dance. The Mukomuko District Government also carried out various activities so that sunai was increasingly recognized by the community.

Keywords: sunai, musical function, preservation, multiethnic
\end{abstract}




\section{PENDAHULUAN}

Kesenian merupakan salah satu unsur budaya yang paling menonjol, dan kesenian itu sendiri terdiri dari banyak cabang serta macam. Di antaranya adalah musik, tari, dan sastra yang merupakan hasil seni budaya suatu daerah yang sangat erat hubungannya dengan lingkungan masyarakat pendukungnya. Hal ini menunjukkan bahwa seni tradisonal tidak berdiri sendiri dan tidak dapat terlepas dari masyarakat pendukungnya apabila keberadaannya masih difungsikan sebagai salah satu bagian kehidupan. Kesenian merupakan pengungkapan kreatifitas manusia dengan masyarakat sebagai penyanggahnya. Keberadaannya tidak mandiri tetapi luluh lekat dengan adat, pandangan hidup, tata masyarakat, kepercayaan yang secara turun temurun telah diakui keberadaannya oleh masyarakat di lingkungan kebudayaan itu lahir.

Masuknya berbagai etnis ke wilayah Propinsi Bengkulu serta adanya pengaruh dari budaya yang dibawa oleh kolonial sehingga memunculkan budaya baru. Menurut beberapa catatan, masyarakat Melayu Bengkulu sendiri merupakan perpaduan (asimilasi) budaya rejang dan minangkabau dan mendapat pengaruh dari berbagai etnis yang datang ke Bengkulu seperti Bugis, Cina, Arab, Jawa, Aceh, Palembang, dan India (Anwar, 2004:273). Demikian juga daerah lainnya seperti wilayah Mukomuko yang diyakini memiliki hubungan erat dengan suku bangsa Minangkabau (Refisrul dan Seno, 2016).

Perpaduan berbagai budaya ini membawa pengaruh dalam bidang kesenian yang sering ditampilkan pada acara-acara adat maupun perayaanperayaan tertentu. Perkembangan selanjutnya semakin banyak jenis kesenian yang menjadi khas Propinsi Bengkulu seperti gamat, talibun, tari selendang, tari sapu tangan, pencak silat, tari mabuk, tari piring, gandai, kejei, dan lain-lain. Disamping itu terkait dengan agama Islam terdapat juga kesenian hadra, syarafal anam, dan qasyidah (Hamidy (Ed). 1991/1992: 53; Iriani, dkk. 2006: 97 - 106).

Di Kabupaten Mukomuko terdapat kesenian yang sudah dikenal secara luas oleh masyarakat yaitu Tari Gandai. Tari Gandai diyakini berasal dari mitologi Malin Deman di wilayah Kecamatan Malin Deman Kabupaten Mukomuko. Malin Deman sendiri diyakini sebagai nenek moyang suku bangsa Pekal yang 
menciptakan tari gandai beserta alat musik pengiringnya yaitu gendang dan seruni (sunai) (Refisrul dan Seno, 2016).

Serunai Mukomuko atau dalam bahasa Pekal disebut sunai (selanjutnya akan disebut sunai) merupakan alat musik utama pengiring tari gandai. Alat musik ini memiliki kekhasan sendiri yang berbeda dengan alat musik serunai lainnya di beberapa daerah. Salah satu kekhasan alat musik ini adalah bahan hanya terbuat dari potongan ruas bambu yang disambung-sambung sedemikian rupa ditambah dengan penghasil suara dari daun kelapa. Kesederhanaan alat musik ini mampu mengiringi berbagai lagu-lagu untuk tari gandai. Keberadaan alat musik sunai di wilayah Kabupaten Mukomuko masih tetap bertahan seiring dengan keberadaan tari gandai itu sendiri. Meskipun demikian, alat musik ini belum sepopuler tari gandai itu sendiri dalam arti belum banyak anggota masyarakat yang memahami dan mampu memainkan alat musik tersebut.

Secara konsep serunai atau Sunai adalah alat musik tradisional tiup aerophone, tergolong dalam end blown flute yang berfungsi sebagai pembawa melodi yang dikembangkan (improvisasi) dan dimainkan oleh satu orang. Alat musik ini diyakini berasal dari suku bangsa Pekal yang ada di Kecamatan Malin Deman Kabupaten Mukomuko dan berkembang hingga ke seluruh wilayah Kabupaten Mukomuko. Penyebaran ini menyebabkan adalah beberapa istilah penyebutan yang berbeda pada masing-masing kecamatan sesuai dengan dialek bahasa di daerah tersebut. Beberapa penyebutan terhadap serunai atau Sunai adalah seghonai (penyebutan untuk wilayah suku bangsa Mukomuko), serunai untuk penyebutan secara umum, dan Sunai untuk penyebutan oleh suku bangsa Pekal di Kecamatan Malin Deman.

Mengacu pada penamaan serunai (istilah yang umum dipakai dalam bahasa Indonesia). Kamus Besar Bahasa Indonesia edisi daring (https://kbbi.kemdikbud.go.id/entri/serunai diunduh 30 Januari 2019 pukul 14.27), kata serunai berarti ( $n$ Mus) alat musik tiup jenis klarinet yang dibuat dari kayu. Sedangkan jika merujuk pada asal usul pengunaan nama serunai diyakini berasal dari wilayah Persia atau India Utara dengan sebutan shehnai atau sanai. Sebutan ini berawal dari seseorang yang memainkan nai (menyerupai pipa) dengan nada- 
nada yang menyenangkan raja (shah) hingga akhirnya alat musik tersebut (nai) disebut shehnai (pipa atau sejenis tabung yang terbuat dari kayu yang menyenangkan raja) (Ranade, 2006:307). Istilah inilah yang diadopsi hingga ke berbagai wilayah di Indonesia.

Mukomuko dengan latar belakang budaya yang multietnis dan terbuka terhadap budaya luar semakin memudahkan unsur budaya luar diterima dan diadaptasikan dalam kehidupan sehari-hari. Salah satu unsur budaya tersebut adalah kesenian gandai yang disepakati berasal dari kesenian suku bangsa Pekal di Kecamatan Malin Deman Kabupaten Mukomuko. Penerimaan masyarakat terhadap kesenian gandai diikuti dengan penerimaan terhadap alat musik sunai. Alat musik sunai bukan hanya sebagai alat musik pengiring tari gandai tetapi menjadi ikon Kabupaten Mukomuko dalam mempersatukan keberagaman budaya. Dari uraian tersebut muncul pertanyaan bagaimana fungsi sunai dan bagaimana upaya pelestariannya sehingga bisa diterima oleh masyarakat. Untuk menjawab pertanyaan tersebut penelitian ini akan menjelaskan sejarah dan deskripsi sunai, proses persebaran, dan upaya pelestarian yang dilakukan oleh masyarakat dan pemerintah.

Kebudayaan ditinjau dari wujudnya paling sedikit mempunyai tiga wujud, yaitu wujud sebagai suatu komplek gagasan, konsep, dan pikiran manusia, wujud sebagai komplek aktivitas, wujud sebagai benda. Dari tiga wujud tersebut secara universal kebudayaan terdiri dari 7 unsur yaitu: (1) bahasa, (2) sistem teknologi, (3) sistem mata pencarian hidup atau ekonomi, (4) organisasi sosial, (5) sistem pengetahuan, (6) religi, dan (7) kesenian (Koentjaraningrat, 2013: 164-170 dan $202-204)$.

Sifat universal tersebut berarti setiap suku bangsa memiliki ketujuh unsur tersebut dengan bentuk dan pemaknaan yang berbeda-beda. Demikian pula halnya pada unsur kesenian, dengan bentuk dan pemaknaan masing-masing, kesenian diciptakan oleh manusia untuk mendapatkan rasa keindahan. Dengan mengutip tulisan Selo Sumardjan, Martarosa (2002). mengatakan bahwa kesenian bersumber pada rasa, terutama rasa keindahan yang ada pada manusia dan dapat disentuh lewat panca indra. 
Eksistensi kesenian dalam masyarakat terkait dengan fungsi dan guna kesenian tersebut bagi masyarakat tersebut. Secara konseptual, fungsi berarti hubungan fungsi tersebut dengan organisme sosial. Martosa mengutip pendapat S. Budhisantoso yang mengatakan bahwa terdapat delapan macam fungsi sosial yaitu sebagai: (1) sarana kesenangan; (2) bersantai atau hiburan; ungkapan jati diri; (3) sarana jati diri; (4) sarana integratif; (5) sarana penyembuhan (therapeutic significance); (6) sarana pendidikan; (7) sarana integrasi dalam masa kacau; (8) lambang yang penuh makna dan mengandung kekuatan (Budhisantosa, 1991). Sedangkan Soedarsono melihat fungsi seni, terutama dari hubungan praktis dan integritasnya, mereduksi menjadi tiga fungsi utama, yaitu: (1) untuk kepentingan sosial atau sarana upacara; (2) sebagai ungkapan perasaan pribadi yang dapat menghibur diri; dan (3) sebagai penyajian estetik (Soedarsono, 1995).

Merriam (1980:209-2010) membedakan guna dan fungsi (uses and functions) musik dalam masyarakat. Merriam menjelaskan fungsi dalam hal ini berkaitan dengan alasan musik itu dipakai atau dinikmati oleh seseorang atau kelompok tertentu yang dengan musik tersebut akan tercapai tujuan yang diharapkan. Sedangkan guna musik adalah dalam aspek penggunaannya seperti untuk dinikmati sendiri atau kelompok tertentu sesuai dengan fungsi musik tersebut

Lebih lanjut Merriam (1980:223-227) mengatakan terdapat 10 fungsi musik pada masyarakat yaitu:

1. Fungsi musik sebagai pengungkapan emosional

Fungsi musik dalam hal ini berarti sebagai sarana pengungkapan perasaaan seseorang baik pemusik itu sendiri maupun orang lain yang menikmatinya. Ungkapan perasaan bisa dalam bentuk kegembiraan, kesedihan, atau hal lainnya sesuai dengan pengalaman orang tersebut;

2. The function of aesthetic enjoyment.

Dalam hal ini musik berfungsi sebagai ungkapan rasa keindahan dalam hal menikmati keindahan sesuatu;

3. The function of entertainment. 
Dalam hal ini musik sebagai alat hiburan yang bisa membangkitkan semangat maupun kesenangan;

4. The function of communication

Fungsi musik dalam hal ini menggambarkan kekhasan suatu daerah dengan irama musik tertentu dan alat musik tertentu yang bisa dipahami oleh pendengar (penikmat) sebagai milik suatu daerah;

5. The function of symbolic representation

Musik berfungsi sebagai representasi simbolik yang bisa dilihat dari irama musik, tempo, lirik, dan lain-lain. Musik dengan tempo lambat disimbolkan sebagai musik yang sedih. Demikian juga musik dengan tempo cepat bisa disimbolkan sebagai musik pembangkit semangat atau gembira;

6. The function of physical response

Musik mampu memberikan respon terhadap psikis manusia mengikuti irama musik yang didengarnya. Musik dengan tempo lambat cendrung orang yang mendengarnya tidak akan memberikan respon dalam gerak fisik, sebaliknya musik dengan tempo cepat akan memberikan respon yang aktif terhadap fisik;

7. The function of enforcing conformity to social norms.

Pada masyarakat tradisional atau masyarakat adat tertentu, musik sering dipakai sebagai sarana sosialisasi terhadap nilai-nilai budaya dalam komunitasnya atau ethnic group-nya;

8. The function of validation of social institutions and religious rituals.

Pada setiap suku bangsa secara universal musik sering dipakai sebagai pengiring aktivitas adat seperti upacara terkait daur hidup;

9. The function of contribution to the continuity and stability of culture

Seperti halnya fungsi musik sebagai sarana sosialisasi norma sosial, dalam hal ini juga musik berfungsi untuk menjaga keberlangsungan sebuah kebudayaan. Artinya dengan tetap eksisnya musik tradisi sebuat suku bangsa, maka identitas budaya suku bangsa tersebut bisa terjaga;

10. The function of contribution to the integration of society 
Musik mampu menjadi alat pemersatu masyarakat baik yang berbeda latar belakang agama, budaya, dan identitas lainnya. Seperti contoh musik dangdut, jazz, atau lainnya bisa saja diminati oleh kelompok yang berbeda latar belakangnya sehingga terbentuk sebuah komunitas atau masyarakat penikmat musik tertentu.

Lestari (2012) dalam tulisannya menjelaskan pengertian musik daerah sebagai suatu bentuk karya seni yang menggunakan medium suara atau bunyibunyian, yang hidup dan berkembang di tengah masyarakat yang sesuai dengan aturan-aturan daerah setempat yang di lakukan secara turun menurun dan pembelajarannya dilakukan secara oral. Musik daerah kebanyakan merupakan warisan leluhur sehingga tidak diketahui siapa pencentusnya dan tidak menonjolkan sikap perorangan karena musik daerah adalah milik suatu golongan suku bangsa. Berdasarkan fungsi musik tersebut dapat dijadikan sebagai unsur pembeda identitas budaya suatu daerah (Clarke, 2008:2). Secara konseptual, Samovar (2010:184) menjelaskan identitas budaya sebagai identifikasi komunikasi dari sistem perilaku simbolis verbal dan nonverbal yang memiliki arti dan yang dibagikan di antara anggota kelompok yang memiliki rasa saling memiliki dan saling membagi tradisi, warisan, bahasa, dan norma-norma yang sama.

Secara konseptual, Permendikbud No. 10 tahun 2014 tentang Pedoman Pelestarian Tradisi Pasal 1 menjelaskan bahwa:

"Pelestarian tradisi adalah upaya pelindungan, pengembangan, dan pemanfaatan suatu kebiasaan dari kelompok masyarakat pendukung kebudayaan yang penyebaran dan pewarisannya berlangsung secara t u r u n - temurun".

Salah satu usaha yang dilakukan dalam rangka pelestarian tradisi adalah dengan pelindungan yang dapat dilakukan dengan berbagai kegiatan seperti pendokumentasian tradisi dan pengkajian terhadap aspek tradisi yang akan dilestarikan. Upaya lain adalah dengan melakukan pengembangan dan pemanfaatan aspek tradisi agar dikenal oleh masyarakat pendukungnya maupun oleh masyarakat luas. 


\section{METODE PENELITIAN}

Penelitian ini menggunakan metode penelitian kualitatif deskriptif yang bersifat holistik-integratif, thick description, dengan analisa deskriptif kualitatif. Penelitian dilakukan di Kabupaten Mukomuko dengan fokus pengumpulan data di Kecamatan Malin Deman sebagai daerah asal tari gandai dan sunai, Kecamatan Air Dikit sebagai wilayah pengembangan sunai dan gandai di wilayah tengah, Desa Talang Petai sebagai wilayah pengembangan sunai dan gandai di wilayah utara. Dengan fokus pada 3 wilayah berdasarkan posisi geografis Kabupaten Mukomuko diyakini telah mewakili pola persebaran sunai dan gandai sehingga keakuratan data dapat dipercaya.

Pengumpulan data dilakukan dengan melakukan wawancara, pengamatan di 3 lokasi yang telah dikunjungi, dan studi dokumentasi. Wawancara di Kecamatan Malin Deman Desa Serami Baru telah dilakukan terhadap 3 orang informan yang berasal dari 1 orang pemain sunai, dan 2 orang tokoh adat yang difokuskan pada aspek sejarah Malin Deman dan sejarah sunai dan gandai. Di Kecamatan Air Dikit wawancara dilakukan terhadap 1 orang pemain sunai dan kareografer tari terkait bahan dan bentuk sunai, cara memainkan, dan nada yang dihasilkan. Di Desa Talang Petai Kecamatan V Koto wawancara dilakukan terhadap 2 orang pemain sunai terkait sejarah, dialek penamaan terhadap sunai, dan pertunjukan sunai dan gandai. Satu orang informan lainnya adalah sebagai informan utama yang selalu mendampingi peneliti dalam pengumpulan data serta menjelaskan data yang telah dikumpulkan. Informan utama juga memberikan informasi yang dibutuhkan selama proses pengamatan

\section{PEMBAHASAN}

\section{Sejarah Sunai}

Sejarah serunai (Sunai) di Kabupaten Mukomuko sangat erat hubungannya dengan sejarah munculnya tari gandai. Masyarakat Kabupaten Mukomuko meyakini bahwa tari gandai berasal dari mitologi Malin Deman di Kecamatan Malin Deman Kabupaten Mukomuko saat ini yang masuk dalam wilayah budaya Pekal. 
Sebagai gambaran bahwa suku bangsa Pekal merupakan salah satu suku bangsa yang mendiami Kabupaten Mukomuko khususnya di Kecamatan Malin Deman, Kecamatan Ipuh, dan Kecamatan Pondok Suguh. Suku bangsa Pekal juga bermukim di wilayah Kabupaten Bengkulu Utara khususnya di Kecamatan Ketahun. Kedua wilayah ini merupakan wilayah budaya suku bangsa Pekal dan mimiliki kesamaan sejarah dan budaya. Dengan demikian Sunai juga dikenal oleh suku bangsa Pekal yang ada di Kecamatan Ketahun (baca Pakpahan, 2014).

Mitologi Malin Deman pada dasarnya memiliki beragam versi yaitu versi oleh suku bangsa Pekal, versi oleh suku bangsa Minangkabau, dan versi umum yang diketahui di Kabupaten Mukomuko. Meskipun ada perbedaan diantara kisah Malin Deman pada masyarakat Mukomuko dan masyarakat Pekal, namun kisah itu pada hakikatnya mengandung isi dan makna yang sama (Sarwono, 2005 ; 96). Menurut penuturan Firman dan Asmawi (Wawancara di Desa Serami Baru Kecamatan Malin Deman, 13 Desember 2018), bahwa cerita Malin Deman memang benar terjadi dan lokasinya persis di sekitar Desa Serami Baru. Sedangkan letak batu dan sungai yang disebutkan dicerita adalah Sungai Ipuh dan Malin Deman mengambil bambu (telang) untuk Sunai di tepi Sungai Ipuh.

Di lokasi tersebut Malin Deman membuat serunai (Sunai) dari bambu (telang) mengiringi tarian tersebut. Malin Deman membuat alat musik seperti sunai dari buluh bambu dan membunyikannya untuk mengenang Puti Bungsu yang telah kembali ke langit (negeri kayangan). Demikian pula, di menyuruh hambanya Selamat membuat redap (rebana) untuk mengiringi tari melengkapi bunyi serunai (Nursyamsiah,1997; 6-7).

Terkait dengan pembuatan Sunai, selanjutnya diceritakan oleh Asmawi, akibat kesedihan Malin Deman, ia merenung di tepi Sungai Ipuh sambil membuat alat musik dari bambu (telang kapa) yang berada di tepi sungai tersebut. Ia membuat memotong bambu tersebut menjadi 5 ruas yang besar, 4 ruas kecil, dan lubang sebanyak 6 buah. Proses pembuatan lubang ini memakan waktu yang cukup lama yaitu ketika burung elang melayang di udara dan menghasilkan suara, maka Malin Deman membuat lubang satu demikian seterusnya hingga terdapat 6 lubang. Belum diketahui secara pasti kenapa bambu tersebut harus 9 ruas dan 
lubang harus 6. Namun menurut perkiraan Asmawi, kemungkinan sebagai manifestasi dari 6 saudara Puti Bungsu menari menghiburnya. Sedangkan 9 ruas bambu diperkirakan sebagai 7 orang putri dari Negeri Kayangan bersama 2 orang tua mereka. Gerakan tari gandai juga diyakini sebagai perwujudan dari gerak para putri kayangan ketika hendak turun ke bumi untuk mandi. Demikian juga sebagai gambaran ketika burung elang melayang-layang di atas Malin Deman saat merenungi nasibnya (Wawancara dengan Asmawi di Desa Serami Baru Kecamatan Malin Deman, 13 Desember 2018). Keterkaitan tari gandai dengan cerita atau mitos Malin Deman dan Puti Bungsu dipertegas oleh Bukori (dalam Nursyamsiah 1997; 6-7, dan Eni Suanti, 2011; 4), yang menyatakan bahwa tari gandai berasal dari proyeksi, dramatisasi dan cerminan dari cerita Malin Deman dan Puti Bungsu yang ditokohi oleh dewa-dewi yaitu Puti Bungsu dan Malin Deman makhluk setengah dewa.

Berdasarkan mitologi Malin Deman tersebut, maka bisa disimpulkan bahwa tari gandai dan Sunai berasal dari Kecamatan Malin Deman Kabupaten Mukomuko. Kesimpulan ini juga didukung oleh pengakuan masyarakat di Kabupaten Mukomuko termasuk para seniman gandai dan Sunai bahwa kesenian ini berasal suku bangsa Pekal di Kecamatan Malin Deman.

\section{Spesifikasi Sunai}

\section{Bahan dan Pembuatan Sunai}

Sunai terbuat dari bambu kappa atau telang kapa yang hidup di tepi sungai (umumnya banyak ditemui di sepanjang Daerah Aliran Sungai Ipuh). Menurut Dawam (Wawancara 11 Desember 2018 di Air Dikit), orang Mukomuko mengenal beberapa jenis bambu (aur, bahasa Mukomuko, atau telang bahasa Pekal), yaitu jenis kappa (1), aur berduri, aur licin, dan aur kuning. Dari beberapa jenis bambu tersebut, yang dianggap terbaik adalah telang kappa karena tekstur bambu tersebut lebih tipis, mudah untuk diolah, dan menghasilkan suara yang lebih nyaring. Bambu yang dipakai harus dari satu jenis dan tidak boleh dicampur dengan jenis lain karena bisa menghasilkan suara yang tidak baik. Selain itu agar pembuatan serunai lebih baik dan lebih mudah dalam penyambungan, bambu 
yang dipakai harus yang berasal dari satu batang yang sama karena sudah memiliki ukuran yang pas untuk di setiap ruasnya.

Ada beberapa keyakinan masyarakat atau pembuat Sunai terkait pemilihan bambu untuk Sunai yaitu:

1. Bambu yang tumbuh condong ke arah air diyakini akan menghasilkan suara yang lebih baik;

2. Bambu yang tumbuh condong ke arah jalan diyakini akan banyak diminati orang;

3. Bambu yang terdapat sarang semut diyakini Sunai yabg dibuat memberikan daya tarik tersendiri bagi pemain maupun orang melihat Sunai tersebut;

4. Bambu yang tumbuh tegak lurus diyakini sangat memudahkan dalam pembuatan Sunai karena tidak terlalu sulit memilih ruas yang akan dipakai namun dianggap tidak memiliki keistimewaan atau daya tarik bagi pemain maupun penonton.

Bambu yang dipilih adalah bambu yang telah cukup tua tetapi tidak boleh yang sudah mati di rumpun bambu tersebut. Batang bambu harus yang lurus dan memiliki ukuran yang ideal untuk dijadikan sunai pada setiap ruasnya sebanyak 9 ruas. Selanjutnya bambu yang telah diambil diuji kelayakannya sesuai dengan keyakinan masyarakat lokal yaitu dengan menghayutkan batang bambu yang telah ditebang tersebut ke tepi sungai. Jika bambu tersebut memudiki sungai, maka bambu tersebut dianggap bambu yang baik. Tetapi jika bambu tersebut hanyut mengikuti aliran sungai ke hilir maka bambu tersebut tidak baik. Hal ini terkait dengan mitologi Malin Deman ketika Malin Deman hendak membuat sunai dan melihat ada bambu yang memudiki sungai dan menjadikan bambu tersebut sebagai bahan sunai. Selanjutnya bambu dijemur kurang lebih 3 hari atau hingga benar-benar kering agar ketika dipotong bambu tersebut tidak mengkerut.

Sunai terdiri dari 9 ruas dengan ukuran yang berbeda-beda yaitu:

1. Ruas pertama paling ujung dan terbesar berukuran panjang satu genggam tangan (5 jari) ditambah satu 1 jari jempol atau sekitar $12 \mathrm{~cm}$ diameter 
bagian bambu terbesar sekitar 6-7 $\mathrm{cm}$. Sedangkan untuk penyambung sekitar $1 \mathrm{~cm}$ (ukuran ini tergantung pada kondisi bambu masing-masing).

2. Ruas kedua sepanjang satu genggam (5 jari) atau sekitar $8-9 \mathrm{~cm}$ dengan diameter sekitar 6-6,5 $\mathrm{cm}$. Jarak penyambung sekitar $3 \mathrm{~cm}$ dan terdapat lubang pelepasan udara dengan diameter lubang sekitar $2 \mathrm{~cm}$.

3. Ruas ketiga sepanjang 4 jari atau sekitar 6,5-7 $\mathrm{cm}$ dengan lubang pertama untuk penentu suara.

4. Ruas keempat sepanjang 3 jari atau sekitar $6 \mathrm{~cm}$ dengan dua lubang dan 1 lubang perantara ke ruas kelima;

5. Ruas kelima sepanjang satu genggam tangan (5 jari) ditambah satu 1 jari jempol atau sekitar $10 \mathrm{~cm}$ dengan 1 lubang di atas sejajar dengan lubang lain dan satu lubang di bawah. Ukuran ini sama dengan ukuran ruas pada bagian pertama di atas.

6. Ruas keenam, ketujuh, kedelapan, dan kesembilan adalah penyambung ruas bambu (disebut batang padi) ke anak sunai (penghasil bunyi) sehingga berukuran sangat pendek.

Pada bagian ujung terkecil Sunai dipasang anak sunai sebagai penghasil bunyi saat ditiup. Anak sunai ini terbuat dari daun muda kelapa (janur) yang diikatkan ke "batang" bulu ayam jantan ${ }^{1}$ yang telah dilubangi sebagai saluran udara dari mulut peniup ke daun kelapa sehingga menghasilkan bunyi. Anak sunai ini disambungkan ke ruas bambu Sunai terkecil (penyambung sunai diistilahkan dengan batang padi). Daun kelapa sebagai bagian dari anak sunai dilipat dua dipotong sekitar $1 \mathrm{~cm}$ sehingga berbentuk segi empat. Selanjutnya bentuk segi empat tersebut dipotong pada bagian kiri dan kanan sehingga berbentuk segi tiga tetapi pada bagian lain tidak dipotong tetapi disisakan sesuai ukuran pipet (bulu ayam). Selanjutnya daun kepala tersebut diikat dengan benang ke bulu ayam dan pada bagian atas atau bagian lipatan daun kelapa dipotong sedikit pada bagian sudut kiri dan kanan lalu pada bagian lipatan dipisahkan dengan memotong tepat pada lipatan. Bagian inilah yang menghasilkan bunyi saat

\footnotetext{
${ }^{1}$ Saat ini bulu ayam tersebut lebih banyak diganti dengan pipet minuman air kemasan ukuran gelas karena dianggap lebih tahan lama.
} 
ditiup sedangkan bambu Sunai berfungsi sebagai pembesar suara dan pengatur nada. Antara anak sunai dengan penyambung Sunai dipasang depang yang terbuat dari uang koin sebagai pembatas antara mulut peniup dengan Sunai.
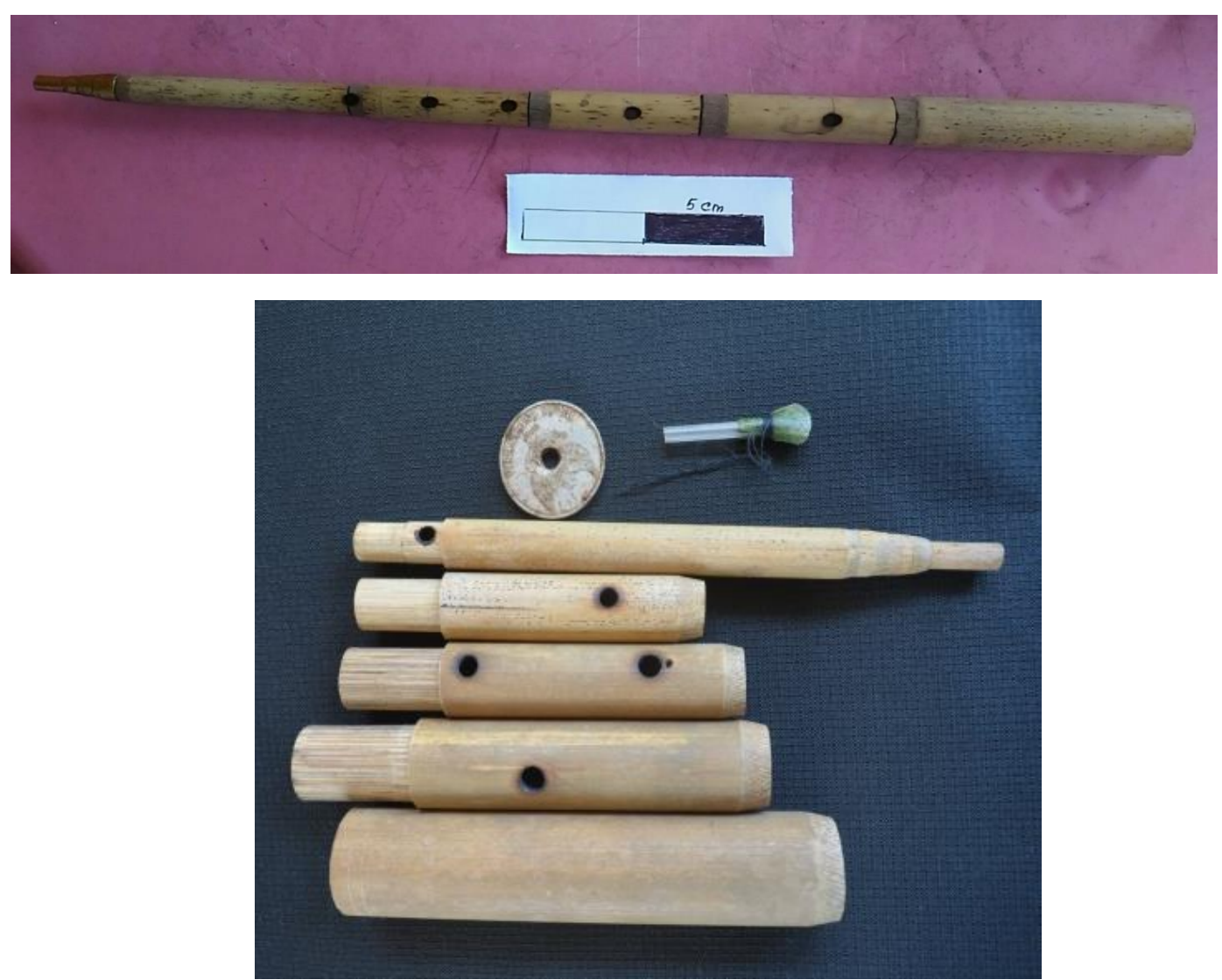

Gambar 1. Bentuk utuh Sunai dan bagian-bagiannya

Penentuan jarak antarlubang pada sunai tergantung pada si pembuat sunai.

Standar ukuran yang selalu dipakai adalah tangan si pembuat seperti penentuan jarak antarruas yang telah dijelaskan di atas. Untuk menentukan lubang pertama dan terakhir pada sunai dilakukan dengan beberapa cara salah satunya adalah dengan mengukur jarak antara ujung jari telunjuk dengan jari jempol dalam posisi siku. Jarak ini sebagai acuan untuk menentukan jarak antarlubang berikutnya. Lubang kedua berjarak satu ukuran jempol pembuat, jarak lubang kedua dengan lubang ketiga berjarak satu jempol pembuat, jarak lubang ketiga dengan lubang keempat berjarak 3 jari pembuat. 
Sebagian besar para pemain sunai dan pembuat sunai masih meyakini bahwa sunai juga mimiliki roh yang harus dihormati dan dipanggil agar masuk dalam sunai. Tujuan memanggil roh tersebut agar tidak mendapat gangguan dari pemain sunai lain saat tampil dan suara yang dihasilkan juga sangat baik. Bahan yang dipakai untuk ritual sunai adalah limau dan kemeyan. Pertama-tama limau digosok ke seluruh bagian sunai lalu diasapi dengan asap kemeyan yang telah dibakar sambil membacakan mantra-mantra

\section{Memainkan Sunai}

Sunai secara fisik dan teknis memiliki kemiripan dengan serunai pada umumnya di Indonesia. Jumlah lubang pada sunai berjumlah 6 buah namun hitungan untuk menghasilkan variasi suara hanya terdapat 4 lubang di bagian atas dan 1 lubang di bagian bawah. Urutan penomoran lubang adalah sebagai berikut: lubang pertama adalah lubang yang berada dekat dengan anak sunai yang ditiup, lubang selanjutnya adalah lubang bagian bawah (berada di bawah lubang pertama), selanjutnya lubang kedua yang berada di bawah lubang pertama, lalu lubang ketiga, dan lubang keempat. Dengan demikian hanya lubang 1, 2, 3, 4, dan lubang bawah yang dipakai untuk variasi suara. Sedangkan lubang kelima tidak dipakai hanya difungsikan untuk pelepasan suara atau nafas jika sunai dikombinasikan menutup lubang dengan kaki untuk memperoleh variasi suara.

Suara dihasilkan dari anak sunai yang berada pada bagian terkecil dari sunai ditiup dengan teknik tertentu untuk menghasilkan suara. Variasi suara (lebih tepat disebut variasi suara dari pada nada karena suara yang dihasilkan belum dapat dituliskan dalam notasi lagu) dihasilkan dari teknis meniup, membuka dan menutup lubang, dan bantuan kaki untuk menutup lubang ujung sehingga muncul variasi suara. Suara alat musik sunai yang tidak dapat dituliskan dalam notasi nada standar, juga terjadi pada beberapa alat musik daerah lainnya di Indonesia seperti silu dan serunai di daerah Bima (Depdikbud, 1992:52-53).

Pengklasifikasian variasi suara yang dihasilkan sunai dikelompokkan pada: 
1. Suara tertinggi, suara ini dihasilkan dari sunai jika seluruh lubang tidak ditutup atau dibiarkan terbuka.

2. Suara tinggi, suara ini dihasilkan dari sunai jika lubang pertama (dekat anak sunai) ditutup dan lubang lainnya terbuka.

3. Suara agak tinggi, suara ini dihasilkan dari sunai jika lubang pertama dan lubang bagian bawah (di bawah lubang pertama) ditutup bersamaan dan lubang lainnya terbuka.

4. Suara rendah, suara ini dihasilkan dari sunai jika lubang pertama, lubang bagian bawah, dan lubang kedua ditutup bersamaan sedangkan lubang lainnya terbuka.

5. Suara lebih rendah, suara ini dihasilkan dari sunai jika lubang pertama, lubang bagian bawah, dan lubang kedua, dan lubang ketiga ditutup bersamaan sedangkan lainnya dibiarkan terbuka.

6. Suara terendah, suara ini dihasilkan dari sunai jika lubang pertama, lubang bagian bawah, dan lubang kedua, lubang ketiga, dan lubang keempat ditutup bersamaan sedangkan lubang kelima dibiarkan terbuka.

Teknik memainkan sunai sangat bervariasi pada setiap pemain. Pengaturan nafas dan memainkan anak sunai di dalam mulut agar dihasilkan suara yang diinginkan memerlukan keahlian khusus. Bagi pemain sunai yang baru, mengatur pernafasan merupakan permasalahan yang paling sulit karena suara sunai harus tetap terdengar dan tidak boleh putus selama tari gandai masih dimainkan. Teknik pernafasan yang harus dipelajari dan dilatih adalah bagaimana menghirup udara dari hidung tanpa menghentikan suara sunai. Untuk ini pemain sunai sangat terbantu dengan adanya depang (mirip uang koin) sebagai penahan udara dari mulut agar tidak langsung habis saat dihembuskan ke sunai. Saat akan memulai memainkan sunai, pemain sunai mengumpulkan udara di dalam mulutnya lalu ditiupkan secara perlahan ke anak sunai hingga mengeluarkan suara. Saat udara terasa semakin sedikit secepat mungkin udara ditarik kembali dari hidung dan mengumpulkannya kembali di dalam mulut.

Tidak ada standar suara sunai yang bisa dituliskan dalam not lagu, seluruh lagu yang dimainkan dengan alat musik sunai berdasarkan perasaan dan 
pemahaman yang kuat terhadap jenis suara sunai. Dengan pemahaman ini maka lagu-lagu yang diminta oleh penonton akan bisa dimainkan. Keterbatasan jenis variasi suara (6 suara) ${ }^{2}$ sunai juga membuat tidak semua lagu bisa diiringi oleh sunai kecuali lagu-lagu yang memang diciptakan untuk mengiringi tari gandai.

Ramadhan Suyitno (Wawancara tanggal 13 Desember 2018 di Mukomuko) mengatakan sampai saat ini belum bisa distandarkan suara sunai karena setiap sunai memiliki suara tersendiri. Jika satu sunai dimainkan dan berhasil dituliskan tangga nadanya, tidak bisa dipakai untuk sunai lainnya. Bahkan jika sunai yang sama dimainkan dengan lagu yang sama (diulang), belum tentu sesuai dengan tangga nada yang telah dituliskan sebelumnya. hal inilah yang membuat sunai menjadi unik dan tidak bisa ditiru oleh alat musik modern. Penulisan tangga nada sunai pernah dilakukan Pakpahan (2014) berdasarkan hasil rekaman suara sunai di Ketahun. Namun menurut Ramadhan Suyitno, suara yang dihasilkan tidak akan persis sama ketika sunai tersebut dimainkan ulang dengan lagu yang sama.

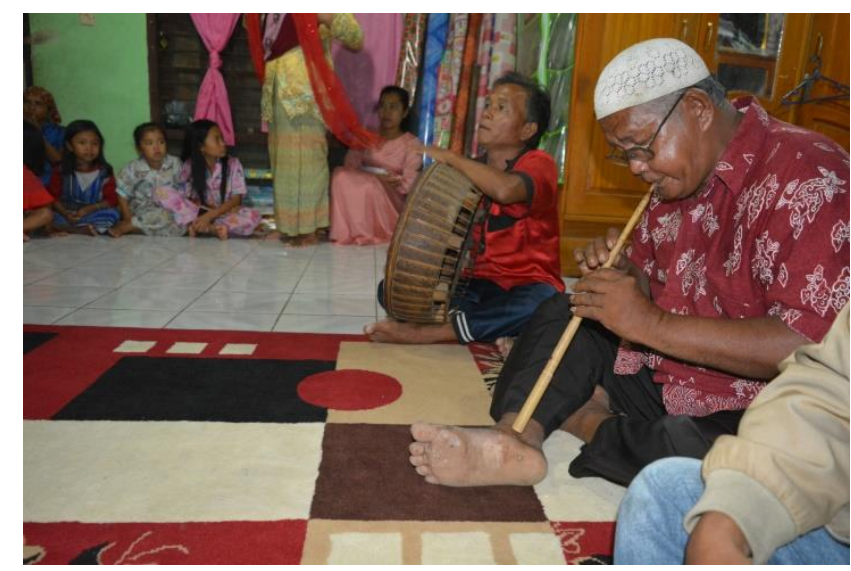

Gambar 2. Salah satu penampilan sunai

Terdapat 9 judul lagu dan gerak tari gandai yang utama dimainkan dalam pertunjukan tari gandai dengan iringan musik sunai dan redap yaitu lori, rantak kudo, siamang berjapai, gajah mandurang, menjong bebek, kuou letok (litak),

\footnotetext{
${ }^{2}$ Saat pengumpulan data, beberapa kali dicoba oleh narasumber untuk membuat nada do, re, mi, fa, sol, la, si, do tidak berhasil, hanya mampu membuat suara sunai yang mirip hingga ke nada sol.
} 
menjong kecil, menjong gedang, puyuh balago, kuou beletuk (litak), nenet, dan cicak di atas loteng.

\section{Fungsi Alat Musik Sunai}

\section{Berangkat dari Malin Deman}

Berangkat dari Malin Deman, gandai dan sunai berkembang hingga menjadi ikon di Kecamatan Malin Deman hingga berkembang hingga keluar Kecamatan Malin Deman. Semakin banyak peminat, penari, dan pemusik gandai semakin eksis di beberapa daerah hingga menjadi ikon Kabupaten Mukomuko.

Beberapa orang yang telah mempelajari kesenian gandai beserta alat musiknya (sunai dan redap) mengembangkannya di daerah lain dengan beberapa pengembangan beberapa tari kreasi gandai dan lagu-lagu pengiring yang semakin bervariasi. Namun perkembangan di luar Kecamatan Malin Deman ternyata tidak diikuti dengan perkembangannya di daerah asalnya. Justru di Kecamatan Malin Deman tidak lagi ditemukan pemain musik dan penari gandai yang mahir. Gandai hanyalah masa lalu di kampung halamannya sendiri. Hanya satu grup gandai yang masih tetap bertahan di Desa Serami Baru walau tidak bisa rutin tampil dan latihan karena terbatasnya pelatih. Untuk pengiring musik sunai hanya satu yaitu Nik Fauzi alias Mamang yang masih dilatih atau dibina oleh Bapak Makrup dari Kecamatan Pondok Suguh.

\section{Fungsi Sunai Sebagai Identitas Mukomuko}

Sunai sebagai alat musik pengiring gandai bukan lagi hanya milik orang Pekal yang ada di Kecamatan Malin Deman, tetapi sudah menjadi milik masyarakat dan ikon Kabupaten Mukomuko. Persebaran sunai merata di seluruh kecamatan baik sebagai penari, pemusik sunai dan redap, dan juga sanggarsanggar kesenian yang fokus pada kesenian gandai.

Berdasarkan data Dinas Pendidikan dan Kebudayaan Kabupaten Mukomuko, sanggar-sanggar kesenian yang fokus pada kesenian gandai dan sunai adalah sebagai berikut:

1. Sanggar Palito Desa Pondok Kandang Kecamatan Pondok Suguh 
2. Sanggar Sirih Serumpun Desa Dusun Baru Kecamatan Air Dikit

3. Sanggar Payung Bulan Desa Pondok Lunang Kecamatan Air Dikit

4. Sanggar Air Dikit Sakti Desa Kecamatan Air Dikit

5. Sanggar Puti Renung Bulan Desa Lubuk Pinang Kecamatan Lubuk Pinang

6. Sanggar Muar Jaya Desa Pulai Payung Kecamatan Ipuh

7. Sanggar Malin Duano Kecamatan Ipuh

8. Sanggar Putra Kembar Desa Lalang Luas Kecamatan V Koto

9. Sanggar Sekapur Sirih Desa Sari Bulan

10. Sanggar Sungai Runggung Air Pancuran Gading Desa Talang Buai Kecamatan Selagan Raya

Sedangkan para pemain sunai masih sangat terbatas karena tidak semua orang mampu memainkan sunai . Pemain sunai diharus mampu memainkan sunai tanpa henti sesuai dengan durasi tarian. Jika suara sunai terhenti berarti tari gandai harus berhenti karena suara sunai merupakan kunci penggerak tari gandai. Agar suara sunai tidak terhenti dibutuhkan keahlian untuk memainkan nafas sehingga perlu latihan khusus. Disamping itu, dengan tidak adanya nada standar yang dapat dituliskan dalam notasi nada, maka pengetahuan pemain sunai terhadap lagu-lagu pengiring gandai sangat diutamakan. Hal ini tidak bisa dipelajari secara teori tetapi melalui praktek langsung terhadap sunai dan mendengar suara yang dihasilkan.

Beberapa nama pemain sunai di Kabupaten Mukomuko adalah sebagai berikut:

1. Makhrup bertempat tinggal di Kecamatan Pondok Suguh Kabupaten Mukomuko

2. M. Dawam bertempat tinggal di Kecamatan Air Dikit Kabupaten Mukomuko

3. Nik Fauzi alias Mamang bertempat tinggal di Kecamatan Malin Deman Kabupaten Mukomuko

4. Waladi bertempat tinggal di Kecamatan Air Dikit

5. Sol Gar Kecamatan bertempat tinggal di Air Rami

6. Bila Sri bertempat tinggal di Kecamatan Tras Terunjam 
7. Marlis bertempat tinggal di Kecamatan Lubuk Pisang

8. Bahut bertempat tinggal di Kecamatan XIV Koto

9. Takdu bertempat tinggal di Kecamatan Teramang Jaya

10. Marjidin bertempat tinggal di Kecamatan Ipuh

11. Ahmad bertempat tinggal di Kecamatan Mukomuko

Persebaran kesenian gandai dan alat musik sunai juga diikuti perubahan penyebutan alat untuk sunai sesuai dengan dialek bahasa yang di daerah tersebut. Di daerah asalnya di Kecamatan Malin Deman, istilah yang dipakai adalah sunai . Di Kecamatan V Koto Desa Talang Petai digunakan istilah shona, dan bahasa logat umum Mukomuko disebut seghonai.

Penerimaan masyarakat Kabupaten Mukomuko terhadap sunai sebagai bagian dari kesenian mereka, bahwa fungsi sunai sudah menjadi pemersatu masyarakat seperti yang disampaikan oleh Merriam (1980:209-2010) musik sebagai the function of contribution to the integration of society. Dalam hal ini masyarakat Mukomuko tidak lagi melihat sunai dan gandai sebagai milik orang Pekal tetapi menjadi bagian dari masyarakat Kabupaten Mukomuko walaupun secara budaya berbeda suku bangsa. Sunai sebagai pemersatu masyarakat juga terlihat dari peran serta dalam mempelajari dan menjadi pemain musik sunai dengan semakin banyaknya sanggar kesenian yang fokus pada kesenian gandai.

\section{Pelestarian Alat Musik Sunai}

Alat musik sunai yang tersebar di seluruh wilayah Kabupaten Mukomuko menjadi ikon Pemerintah Kabupaten Mukomuko. Peran masyarakat dan pemerintah sangat tampak dalam menjaga keberlangsungan alat musik ini. Bagi masyarakat Kabupaten Mukomuko tidak lagi mempermasalahkan asal usul alat musik sunai, mereka lebih fokus pada bagaimana agar alat musik sunai tetap bisa tampil dan bisa mengiringi tari gandai.

Upaya pelestarian bisa dilakukan dengan berbagai cara seperti pada uraian di atas. Alat musik sunai tidak hanya dikenal dan dinikmati oleh kelompok seniman, tetapi juga oleh masyarakat umum seperti yang terlihat pada lomba desain batik khas Kabupaten Mukomuko yang dilaksanakan oleh Dinas 
Perindustrian, Perdagangan, dan UMKM Kabupaten Mukomuko pada bulan desember 2018. Pada lomba tersebut beberapa motif menampilkan sunai sebagai ikon Kabupaten Mukomuko disamping beberapa gambar lainnya seperti carano, ikan, dan lokan.

Pemerintah Kabupaten Mukomuko juga mendukung upaya pelestarian sunai dengan menjadikan sunai sebagai ikon kabupaten yang berarti menjadi alat pemersatu yang telah diakui oleh pemerintah daerah. Beberapa upaya yang telah dilakukan antara lain:

1. Upaya pengenalan ini menjadi materi pelajaran sekolah dalam pelajaran Muatan Lokal melalui program pengelolaan kekayaan budaya. Kegiatan ini dilaksanakan pada tingkat SLTP dengan materi pelajaran meliputi pengenalan sunai, cara membuat sunai, dan teknik pemakaian meliputi pengaturan nafas dan peletakan jari untuk mendapatkan nada;

2. Pelaksanaan festival tari gandai dengan sendirinya melestarikan tari gandai dan alat musik sunai . Festival tersebut telah menumbuhkan bakat-bakat baru untuk mendalami tari gandai dan alat musik sunai . Hal ini terlihat dari semakin banyaknya para penari gandai yang baru demikian juga semakin bertambahnya setiap tahun para peniup sunai. Dengan kondisi seperti ini tentunya pelestarian tari gandai dan sunai akan tetap tercapai;

3. Pemerintah Kabupaten Mukomuko juga telah menjadikan sunai sebagai salah satu cendramata untuk para tamu pemerintah daerah yang berkunjung ke Mukomuko maupun mengikuti suatu pagelaran kesenian atau kegiatan lainnya ke daerah lain.

\section{PENUTUP}

Setiap suku bangsa memiliki kekayaan budaya masing-masing yang diciptakan untuk kepentinngan kelompok suku bangsanya tersebut. Namun tidak sedikit kekayaan satu suku bangsa menjadi milik bersama satu daerah dan menyebar hingga keluar batas administratif. Ketika kekayaan budaya tersebut bisa diterima oleh masyarakat luas, maka kepemilikannya tidak lagi bisa dibatasi oleh salah satu suku bangsa tetapi dimiliki oleh komunitas yang lebih luas. 
Serunai atau dalam bahasa Pekal disebut sunai merupakan alat musik yang berasal dari suku bangsa Pekal di Kecamatan Malin Deman Kabupaten Mukomuko. Penciptaan alat musik ini sangat terkait dengan mitologi Malin Deman sebagai seorang tokoh yang diyakini juga sebagai orang sakti pencipta tari gandai.

Sunai dan gandai merupakan satu kesatuan yang tidak bisa dipisahkan karena tari gandai hanya bisa dimainkan jika diiringi oleh sunai. Suara sunai merupakan penentu gerak kaki penari ditambah suara redap. Gerak tari yang dimainkan oleh penari sangat ditentukan oleh suara sunai pada saat baru dimulai.

Sunai yang berawal dari Kecamatan Malin Deman selanjutnya berkembang hingga ke seluruh wilayah Kabupaten Mukomuko dan wilayah budaya Pekal di Kabupaten Bengkulu Utara. Namun sangat disayangkan di wilayah Kecamatan Malin Deman, justru kesenian gandai dan pemain sunai sudah sulit ditemukan. Kesenian ini justru lebih gampang ditemui di beberapa kecamatan lainnya di Kabupaten Mukomuko.

Perkembangan dan persebaran sunai hingga ke berbagai daerah di Kabupaten Mukomuko menandakan sunai sudah menjadi alat pemersatu masyarakat yang berbeda latar belakang budaya dan menjadikan sunai sebagai ikon yang bisa diterima oleh masyarakat dan Pemerintah Daerah Kabupaten Mukomuko.

Berbagai upaya telah dilakukan oleh masyarakat dan Pemerintah Daerah Kabupaten Mukomuko agar alat musik sunai tetap eksis dan diminati oleh masyarakat seperti menjadi pelajaran MULOK di sekolah, festival, dan menjadikan souvenir. Upaya ini berhasil menjadi alat musik sunai sebagai ikon Kabupaten Mukomuko.

\section{DAFTAR PUSTAKA}

Anwar, M. Ichwan. 2004. "Warna Budaya Melayu Bengkulu” dalam M. Ikram, dkk. Bunga Rampai Melayu Bengkulu. Bengkulu: Dinas Pariwisata Provinsi Bengkulu 
Budhisantosa. "Pendidikan Seni Dan Globalisasi Budaya Dalam Konteks Sentral Dan Strategis", Makalah Seminar Nasional Pendidikan Seni dan Globalisasi Budaya. ISI Yogyakarta, 12 Desember 1991

Hamidy, Badrul Munir (Ed). 1991/1992. Upacara Tradisional Daerah Bengkulu: Upacara Tabot di Kotamadya Bengkulu. Jakarta: Depdikbud http://www.kamuslife.com/2012/04/musik-daerah-pengertian-danfungsi.html\#sthash.UfYKNQj8.dpuf diakses18 Nopember 2018 pukul 13.35

Iriani, Yondri, Rois Leonard Arios, dan Femmy. 2008. "Kesenian Tradisional: Jenis, Tokoh, dan Penyebarannya di Kota Padang, Bengkulu, dan Palembang". Laporan Penelitian BPSNT Padang

Kamus Besar Bahasa Indonesia dalam https://kbbi.kemdikbud.go.id/entri/serunai diunduh 30 Januari 2019 pukul 14.27

Koentjaraningrat. 2013. Pengantar Ilmu Antropologi. Jakarta: Rineka Cipta

Lestari, Iis. "Musik daerah: Pengertian dan Fungsi Musik daerah" diunduh dari

Martarosa "Musik Gamat Sebagai Musik Prosesi (Sebuah Tinjauan Sosial Budaya)" Dalam Jurnal ANTROPOLOGI FISIP Univesitas Andalas Padang, Tahun IV, No. 6. 2002

Merriam, Alan P. 1980. The Anthropology of Music. Northwestern: Northwestern University Press

Nursyamsiah, 1997. "Mitologi Malin Deman dan Puti Bungsu dalam Tradisi Gandai pada Masyarakat Pekal”. Skripsi Sarjana. FKIP UNIB Bengkulu.

Pakpahan, Frita Anjelina. 2014. "Tradisi Gandai Dalam Konteks Upacara Perkawinan Pada Masyarakat Pekal Di Kecamatan Ketahun, Kabupaten Bengkulu Utara, Bengkulu: Deskripsi Pertunjukan, Perubahan, dan Fungsinya" Skripsi Sarjana. Fakultas Ilmu Budaya Universitas Sumatera Utara

Ranade, Ashok Da. 2006. Music Context: A Concises Dictionary of Hindustani Music. New Dehli: Promilla \& Co Publisher

Samovar, Larry, H, dkk. 2010. Komunikasi Lintas Budaya Edisi 7. Jakarta: Salemba Humanika

Sarwit, Sarwono dkk. 2005, Sejarah dan Adat Istiadat Kabupaten Mukomuko. Mukomuko. Mukomuko: Bappeda Kabupaten Mukomuko

Soedarsono, "Pendidikan Seni Dalam kaitannya dengan keparawisataan". Makalah Seminar Dalam Rangka Peringatan Hari Jadi Jurusan Pendidikan Sendratasik ke-10 FPBS IKIP Yogyakarta, 12 Pebuari 1995 